\title{
THE RDP - WHAT CAN OR OFFER?
}

\author{
HW ITTMANN \\ Decision Support Services Programme \\ CSIR Information Services \\ P O Box 395 \\ Pretoria 0001 \\ South Africa
}

\begin{abstract} South Africa that need attention are quoted, namely:

- meeting basic needs;

- developing our human resources;

- building the economy;

- democratising the state and society; and

- implementing this programme.
\end{abstract}

South Africa has made historical changes during the past six years. With the change of Government in May 1994, the majority party of the Government of National Unity, the ANC, announced its master plan for the new South Africa. That was the birth of the Reconstruction and Development Programme (the RDP). Within the RDP document the five major aspects or problem areas in

This paper outlines what OR can offer to support the RDP. We argue, that although all five of the above are valid in the discussion, the emphasis should be on economic growth and how OR can support this. The challenges and opportunities that exist are enormous for OR, the OR community needs to position itself in such a way that it can impact the RDP itself and the RDP process.

KEYWORDS: Operations Research, Reconstruction and Development, Developing Countries, Problem Structuring, Hard OR and Soft OR. 


\section{INTRODUCTION}

South Africa has possibly been through one of the most interesting and exciting periods of its history. On 2 February 1991 the then President, FW de Klerk, opened Parliament with a very historic speech that changed this country totally. What many people, both internationally and within South Africa, saw as an inevitable road of destruction, even horrific war, turned out to be a model for a peaceful transition to democratisation. This was very evident with the first real general election on 27 April 1994 and the formation of a Government of National Unity thereafter. At the same time the new government, through initiatives of the majority party, the ANC, developed a framework for reconstruction and development of the new South Africa.

The Reconstruction and Development Programme (RDP) is a national plan for South Africa. It was possibly the first time that a government, or political party for that matter, endeavoured to prepare such a comprehensive policy framework. Whether such a document was flawless does not, matter; at least the people in this country now had a plan for the future to work towards.

With such a plan in place it was now imperative and essential to develop detailed plans, support structures, etc. to implement the RDP. Many groups, organizations and individuals, in both the private and public sectors, joined forces to make this happen. Looking back, the initial enthusiasm for the RDP has not materialized, mainly because the efforts required to make it happen were totally underestimated. Many promises were made that created the impression that "utopia" would be in place within a few months. Alas the realization that the RDP is a longer term process has emerged. Many are working towards achieving these goals. It is with this spirit that this paper is written, namely: what can operations research, and operations researchers, offer to achieve the goals and objectives of the RDP? 
If we as operations researchers look back at what we have achieved over the last $\mathbf{3 0}$ to $\mathbf{4 0}$ years in South Africa, I believe most, if not all, the applications have been orientated exclusively towards the "first world" component. This has been the focus, with very little that has been done for those deprived communities of our country. The OR applications themselves have been very diverse with no real penetration in any area or sector of our economy. In some cases like mining, where there were many OR groups attached to mining houses, these have now disappeared almost entirely.

The challenges and opportunities facing South Africa are enormous and this is to a large extent reflected in the RDP programme. Operations research can contribute to this in a very big and significant way: I have no doubt about it. These opportunities are in prioritization, optimal allocation of limited resources, decision support and problem structuring to mention only a few. Many other tools and methodologies can be used in this endeavour.

In this paper we outline very briefly what the RDP programme entails and indicate what has been done by operations researchers in South Africa and in developing countries. What are the problems experienced in this regard? Then we look at the OR approach, both hard and soft OR, and try to indicate how applicable these are for the current situation. Finally some examples are given.

\section{THE RECONSTRUCTION AND DEVELOPMENT PROGRAMME}

In the ANC's RDP publication (1994) this programme is outlined in great detail. It suffices to highlight a few general aspects of this programme.

Firstly, the RDP describes itself as an integrated, coherent socio-economic policy framework. It seeks to mobilise all our people and our country's resources towards the final eradication of apartheid and the building of a democratic, non-racial and non-sexist future. Secondly it is essential that the imbalances in our country that exist side by side be eradicated as far as possible. The six basic principles of the RDP, as outlined in the programme, are: 
- it should be an integrated and sustainable programme;

- a people-driven process;

- peace and security for all;

- nation-building;

- link reconstruction and deveiopment; and

- democratisation of South Africa.

The key programmes of the RDP that were identified are:

- meeting basic needs such as jobs, land, housing, water, electricity, etc.;

- developing our human resources. The emphasis is on empowerment, training, education and people development;

- building the economy. The economy has strengths and weaknesses and the emphasis should be on ensuring that the economy benefits all people;

- democratising the state and society. This is integral to the RDP and by integrating all the above a way is paved for a new democratic order in South Africa; and

- implementing this programme. This will have to be a co-ordinated approach with participation of all levels of government and organizations outside government.

There can be no doubt that the RDP as a vision and concept for the development of a new South Africa is great. Never in the history of this country have we had such a plan on the table. The real challenge was, and still is, to get it implemented. What has also been problematic, as far as the RDP is concerned, is the unrealistic expectations that have been created. Nothing has damaged the RDP up to now more than these expectations. Nevertheless it has to be stated again, as a vision for South Africa, the RDP is great! 


\section{BIGGEST PROBLEMS CURRENTLY IN THE RSA}

South Africa faces many challenges but also many problems. Highest on this list must surely be the unprecedented crime and violence currently prevailing. This situation is affecting everyone in the country, both black and white. There was a time when many people did not experience the effect of crime and violence; it only happened to others. Nowadays we all have either experienced it ourselves, or close family or friends have been hit by it. South Africa has become a society with one of with the highest rates of crime and violence in the world. In day to day life this is a totally abnormal society.

One of the biggest reasons given for the high crime rate is unemployment and the lack of jobs. The level of unemployment is unacceptably high and some sources put the percentage at 40 , the official figure is $29 \%$. What is more disturbing is that this number is seemingly increasing.

The majority of the population in South Africa does not have proper housing, water and sanitation, or electricity. Many people are living in appalling conditions while in many of our cities squatter camps are a normal sight.

Health care is another problem area. To quote from the RDP policy document (1994):

"The mental, physical and social health of South Africans has been severely damaged by apartheid policies and their consequences. The health care and social services that have developed are grossly inefficient and inadequate. There are, by international standards, probably enough nurses, doctors and hospital beds. South Africa spends R550 per capita per annum on health care. This is nearly 10 times what the World Bank estimates it should cost to provide basic public health services and essential clinical care for all, yet millions of our people are without such services or such care. Health services are fragmented, inefficient and 
ineffective, and resources are grossly mismanaged and poorly distributed. The situation in rural areas is particularly bad".

The new government has now introduced free medical care for all children under six years of age and for all homeless children, at government clinics and health centres. The aim is also focused on primary health care. However, resources are a major problem both in terms of financial and human resources. Many locally trained doctors are leaving the country and doctors from overseas are recruited for South Africa. There are other serious problems as well.

Education and training is the other major problem area. These areas are being reformed totally and it is questionable whether it is an improvement. The teacher: child ratio in the classroom is being increased, many teachers are being retrenched, etc. The general perception is that standards are being lowered. In the previously deprived communities science and technology was always neglected with very few students going into mathematics and physics. Basic literacy for a major component of the population is also lacking.

Lastly the expected economic growth is not materializing as predicted. Economic growth was one of the four equally important elements of the RDP. However, in July 1995 the Cabinet decided that achieving accelerated economic growth should be treated as a top priority in South Africa. This reflects a subtle but significant shift in emphasis. It has now been recognized that growth is a fundamental prerequisite without which the achievement of the RDP goals is likely to prove impossible.

\section{ECONOMIC GROWTH - TOP PRIORITY IN THE RSA}

South Africa has made a dramatic political transformation that has raised the hopes of a country and even a continent for a better life for all. Better education, housing and health care for all are desirable but this is expensive and South Africa is a poor country. We do not just need growth but rapid and 
sustained growth. With the population growing at 2,5 percent per annum, the GDP will have to grow at 7 to 8 percent per annum for twenty years to reach even Taiwan's level of GDP per person.

With this as a top priority a Cabinet Committee was formed to give attention to this aspect. There is no doubt that economic growth in South Africa is a fundamental prerequisite for other changes and improvements. This will also assist industry in South Africa, which currently is not competitive in the global environment.

The Worid Competitiveness Report (1993) gives an indication of the investment attractiveness of newly industrialised countries. This is reflected in Table 1. From this it is clear that South Africa is not rated very highly which will make economic growth even more difficult.

\begin{tabular}{|l|c|l|c|}
\hline COUNTRY & POSITION & COUNTRY & POSITION \\
\hline Singapore & 1 & Venezuela & 9 \\
\hline Hong Kong & 2 & Indonesia & 10 \\
\hline Taiwan & 3 & South Africa & 11 \\
\hline Malaysia & 4 & Hungary & 12 \\
\hline Chile & 5 & India & 13 \\
\hline Korea & 6 & Brazil & 14 \\
\hline Thailand & 7 & Pakistan & 15 \\
\hline Mexico & 8 & & \\
\hline
\end{tabular}

Table 1: Investment Attractiveness (1993): Newly Industrialised Countries

A few facts about the economic performance of South Africa are given in Table 2. Again the picture is not very rosy. Many of the current problems listed above will be addressed, albeit indirectly, if we can achieve economic growth that is rapid and sustainable. 
- 17 million people live below the minimum living income level

- Official unemployment is 29 percent

- About 4 million people are employed in the informal sector 300000 new job seekers enter the market each year only 6 percent find employment in the formal sector

Table 2: Economic Performance

\section{OPERATIONS RESEARCH OFFERS THE FOLLOWING}

Operations Research originated during very challenging and difficult times more than 50 years ago. It rose to the occasion and performed admirably in support of the war effort of the Allied forces in World War II. In some instances the current situation in South Africa is similar; our country needs to mobilize all the resources available to implement the RDP. I believe OR is very suitable to make a major contribution and impact in this regard.

Our discipline offers an inherent approach to problem solving that is scientific, structured and very definitely objective. The phases of this structured approach can be defined as:

- $\quad$ Formulate the problem;

- $\quad$ Constructing a mathematical (or quantitative) model;

- Derive a solution from this model;

- Test the model and the solution;

- Establish controls over the solution; and

- Implement the solution.

In many instances this approach leads to a set of powerful tools, mainly implemented as computer software tools for comparing alternative scenarios for example. This approach endeavours to reduce the uncertainty in complex situations. This not only improves the quality of decisions and makes the effect of decisions visible but it also reveals the consequences of possible decisions. 
At the same time, since it is very difficult to quantify everything, it is essential that the intuition, experience and common sense of managers and decision makers prevail. These characteristics are indispensable for any decision making environment.

Where have we applied these skills in the past in South Africa? The examples and applications are many and varied and include applications in the following areas:

- Mining;

- Transportation;

- logistics;

- distribution;

- Environment;

- Defence;

- Agriculture;

- Water Resources; and

- Energy.

The list of application areas is much longer. There can be no doubt that those examples and applications have made significant impacts in industry and the public sector in South Africa. They are all examples of "hard OR", that is, the use of quantitative methods in the problem solving process.

From all the examples and applications of OR in the past, and even up to the present, the majority were for the so-called first world component of our country. Very little, if anything, was done for the third world component or for developing communities.

From the RDP programme it is clear that the focus should be on housing, health care, education, crime and violence, etc. Another perspective is the emphasis 
on meeting basic needs, developing our human resources, building the economy and democratising the state and society. These are the real challenges facing our profession.

\section{OR FOR DEVELOPING COMMUNITIES AND DEVELOPING COUNTRIES}

From the OR literature there are many examples of OR as applied to developing countries. These include a special edition of the European Journal of Operational Research, Volume 49, Number 2, November 1990, Patel (1995), Bornstein and Rosenhead (1990) and Aggarwal (1994). In these papers it appears that OR as practiced in developed countries may not be appropriate for less developed countries. Patel (1994) is of the opinion that OR will have to take a different form from that which has been practiced in first world countries. If special recognition is not given to this, Patel believes the impact of OR will be a tiny fraction of its potential. He believes there are three important factors within a developing country, that need to be recognized and addressed. These are:

- The dependency relationship between managers, operations researchers and resources. There are specific differences in relation to these three facets in developing countries. If one ignores them they can mitigate against meaningful OR application;

- Information Technology. Developments create enormous scope and opportunities for operations research applications in developing countries and communities; and

- Soft technologies facilitate much greater opportunities for participation of more parties in the decision making process. "Hard" OR does not really allow for this.

For the South African situation one must take note of these issues and ensure that there is an awareness of the problem situation. Through proper communication and sharing with others, these problems can be overcome. 


\section{SOFT OR AND PROBLEM STRUCTURING METHODS}

The problems facing South Africa and specifically those of the previously deprived societies can be addressed by "soft" OR or problem structuring methods. These have been shown to be very useful in assisting communities with their specific problems (Ritchie, et al., (1994)). The methodologies that have been developed address messy, changing, ill-defined and unstructured problems. There are various methods that fall into this category namely (Reinhold (1991)):

- Strategic Options Development and Analysis (SODA);

- Soft Systems Methodology (SSM);

- $\quad$ Strategic Choice;

- Robustness Analysis;

- Metagame Analysis; and

- Hypergame Analysis.

All of these methods use different processes in analysing, debating and thinking about a problem. The validity of subjective perceptions and the multiplicity of world views are accepted by these techniques. The aim is not to find the right answers but to discuss the problem, get better insight into it and to find acceptable solutions. Those who have been involved in the process are, in most cases, confident about the decisions.

It is clear that we, the OR community in South Africa, have to get to understand these methods and to start applying them in practice. An example of such an application is the use of facilitation and a structured approach to assist a community college in planning their future (Dixon, et al., (1995)). The workshop was facilitated by the CSIR and a "visual gathering" process was used. This college is an educational institution run by volunteers who are very dedicated and committed to their task. Their biggest problems and weaknesses are funding, marketing of the college and the discipline of students. In their planning 
these issues had to be addressed. There was also the opportunity for the college to become formally registered.

The author is from the CSIR and during the last year we in our organization have been involved in a number of RDP related projects. These are briefly:

\section{(i) A system to transfer business skills}

This is an expert system that is being used to transfer business skills. The system fulfils the role of a business councillor.

(ii) Manpower planning in education

This system was developed for one of the new provinces. The planning system was developed to assist in identifying what skills should be developed, through the education system, to meet the demands in industry and the public sector.

(iii) Water and sanitation system

One of the biggest problems in South Africa is the lack of water and sanitation facilities in many communities. This system is to develop a database on top of a GIS which will then be used to identify and prioritize where the biggest problem areas are in the country. It will also be used to monitor progress.

(iv) The Maputo Corridor

A GIS based model was built as a decision support tool around the development of the corridor between Gauteng and Maputo in Mozambique. "What if" analysis can be performed, etc. The model supports the development of the corridor as a transportation pipe line between Gauteng and Maputo in order to stimulate development of industries around this corridor.

The above indicates the potential contribution of OR to address real problems and in this way contribute towards the RDP. 


\section{THE CONTRIBUTION OF OR}

What we have indicated is the variety of areas within which OR can have an impact. The RDP has created, we believe, many new opportunities and challenges. If the RDP is going to succeed, there is one overriding aspect that must happen and that is economic growth. Without this we will not be able to achieve any of the RDP objectives and things such as unemployment with associated crime and violence will escalate. For the economy to grow, industry must grow, become competitive in a global market and start exporting on a much bigger scale. Here, OR can play an enormous role through traditional, "hard", OR. There are many applications in different areas and the opportunities are plentiful. What, however, is still lacking is an awareness in industry of the value of OR. Possibly here the OR community has failed in its efforts to market OR. Nevertheless, the biggest impact that $O R$ can make and the greatest contribution towards the RDP, is in contributing towards economic growth.

Very few "soft" OR applications exist in South Africa. A much more concerted effort is required to achieve this. However, there are problems. The use and application of these methodologies are very much focussed on developing communities. These communities require a very special approach and, furthermore, they don't have any funds. Funding of these "softer" applications is going to be a major problem. If the OR community is serious in applying these methods a few success stories are needed. This will then add credibility to efforts to get funding and there are indications that this can be obtained from international funding agencies.

\section{CONCLUSIONS}

The author believes that OR has a very special role to play in the new South Africa in support of the Reconstruction and Development Programme. In fact, we have the situation where both developed and developing components in our country can be assisted. The challenges and opportunities are there, we need to grab them and capitalize on them. The emphasis should, however, be on 
applying traditional, or "hard", OR to ensure the required economic growth. In this way OR can contribute in assisting this country to become the gateway to the rest of Africa. Parallel to this our efforts should be to address the areas identified within the RDP where the biggest needs are and also to look out for opportunities where "soft" OR can be applied.

Robert McNamara (1995), former Secretary of State of the United States was a firm believer of OR: "To this day I see quantification as a language to add precision to reasoning about the world. Of course, it cannot deal with issues of morality, beauty and love, but it is a powerful tool too often neglected when we seek to overcome poverty, fiscal deficits, or the failure of our national health programmes". The OR community in South Africa should use this philosophy as its motto!

\section{REFERENCES}

[1] The Reconstruction and Development Programme, ANC document. (1994).

[2] McNamara, R., In Retrospect: The Tragedy and Lessons of Vietnam. (1995).

[3] Ritchie, C., Taket, A. and Bryant, J. (Editors), Community Works - 26 case studies showing Community Operational Research in Action, PAVIC Publications. (1994).

[4] Luck, G.M. and Walsham, G. (Editors), Selected Readings in Operational Research for Developing Countries, Operational Research Society. (1982).

[5] Reinhold, A.J., Rational Analysis Revisited: Proceedings of a One-day Event on Problem Structuring Methods, London, March. (1995). 
[6] Dixon, E. and Drewes, A., Planning the future of SEIDET, CSIR Information Services Contract Report DIS-C 156, Pretoria. July (1995).

[7] Patel, N.R., Different Worlds, Different OR, OR/MS Today, June 1995, 36-38. (1995).

[8] Aggarwal, S.C., Practical Applications of $O R$ in an Underdeveloped Nation, Euopean Journal of Operational Research 77, 357-374. (1994).

[9] Bornstein, C.T. and Rosenhead, J., The Role of Operational Research in Less Developed Countries: A Critical Approach, European Journal of Operational Research, 49, 156-178. (1995). 